\title{
EMPLOYEE ATTITUDES AND JOB SATISFACTION
}

\section{Lise M. Saari and Timothy A. Judge}

This article identifies three major gaps between HR practice and the scientific research in the area of employee attitudes in general and the most focal employee attitude in particular-job satisfaction: (1) the causes of employee attitudes, (2) the results of positive or negative job satisfaction, and (3) how to measure and influence employee attitudes. Suggestions for practitioners are provided on how to close the gaps in knowledge and for evaluating implemented practices. Future research will likely focus on greater understanding of personal characteristics, such as emotion, in defining job satisfaction and how employee attitudes influence organizational performance. (C) 2004 Wiley Periodicals, Inc.

"Happy employees are productive employees." "Happy employees are not productive employees." We hear these conflicting statements made by HR professionals and managers in organizations. There is confusion and debate among practitioners on the topic of employee attitudes and job satisfactioneven at a time when employees are increasingly important for organizational success and competitiveness. Therefore, the purpose of this article is to provide greater understanding of the research on this topic and give recommendations related to the major practitioner knowledge gaps.

As indicated indirectly in a study of HR professionals (Rynes, Colbert, \& Brown, 2002), as well as based on our experience, the major practitioner knowledge gaps in this area are: (1) the causes of employee attitudes, (2) the results of positive or negative job satisfaction, and (3) how to measure and influence employee attitudes. Within each gap area, we provide a review of the scientific research and recommendations for practitioners related to the research findings. In the final section, additional recommendations for enhancing organizational practice in the area of employee attitudes and job satisfaction are described, along with suggestions for evaluating the implemented practices.

Before beginning, we should describe what we mean by employee attitudes and job satisfaction. Employees have attitudes or viewpoints about many aspects of their jobs, their careers, and their organizations. How- 
Evidence even indicates that the job satisfaction of identical twins reared apart is statistically similar. ever, from the perspective of research and practice, the most focal employee attitude is job satisfaction. Thus, we often refer to employee attitudes broadly in this article, although much of our specific focus will concern job satisfaction.

The most-used research definition of job satisfaction is by Locke (1976), who defined it as ". . . a pleasurable or positive emotional state resulting from the appraisal of one's job or job experiences" (p. 1304). Implicit in Locke's definition is the importance of both affect, or feeling, and cognition, or thinking. When we think, we have feelings about what we think. Conversely, when we have feelings, we think about what we feel. Cognition and affect are thus inextricably linked, in our psychology and even in our biology. Thus, when evaluating our jobs, as when we assess most anything important to us, both thinking and feeling are involved.

\section{Gap 1-The Causes of Employee Attitudes}

The first major practitioner knowledge gap we will address is the causes of employee attitudes and job satisfaction. In general, HR practitioners understand the importance of the work situation as a cause of employee attitudes, and it is an area HR can help influence through organizational programs and management practices. However, in the past two decades, there have been significant research gains in understanding dispositional and cultural influences on job satisfaction as well, which is not yet well understood by practitioners. In addition, one of the most important areas of the work situation to influence job satisfaction - the work itself-is often overlooked by practitioners when addressing job satisfaction.

\section{Dispositional Influences}

Several innovative studies have shown the influences of a person's disposition on job satisfaction. One of the first studies in this area (Staw \& Ross, 1985) demonstrated that a person's job satisfaction scores have stability over time, even when he or she changes jobs or companies. In a related study, childhood temperament was found to be statistically related to adult job satisfaction up to 40 years later (Staw, Bell, \& Clausen, 1986). Evidence even indicates that the job satisfaction of identical twins reared apart is statistically similar (see Arvey, Bouchard, Segal, \& Abraham, 1989). Although this literature has had its critics (e.g., Davis-Blake \& Pfeffer, 1989), an accumulating body of evidence indicates that differences in job satisfaction across employees can be traced, in part, to differences in their disposition or temperament (House, Shane, \& Herold, 1996).

Despite its contributions to our understanding of the causes of job satisfaction, one of the limitations in this literature is that it is not yet informative as to how exactly dispositions affect job satisfaction (Erez, 1994). Therefore, researchers have begun to explore the psychological processes that underlie dispositional causes of job satisfaction. For example, Weiss and Cropanzano (1996) suggest that disposition may influence the experience of emotionally significant events at work, which in turn influences job satisfaction. Similarly, Brief (1998) and Motowidlo (1996) have developed theoretical models in an attempt to better understand the relationship between dispositions and job satisfaction.

Continuing this theoretical development, Judge and his colleagues (Judge \& Bono, 2001; Judge, Locke, Durham, \& Kluger, 1998) found that a key personality trait, core self-evaluation, correlates with (is statistically related to) employee job satisfaction. They also found that one of the primary causes of the relationship was through the perception of the job itself. Thus, it appears that the most important situational effect on job satisfaction - the job itself-is linked to what may be the most important personality trait to predict job satisfaction-core selfevaluation. Evidence also indicates that some other personality traits, such as extraversion and conscientiousness, can also influence job satisfaction (Judge, Heller, \& Mount, 2002).

These various research findings indicate that there is in fact a relationship between disposition or personality and job satisfac- 
tion. Even though organizations cannot directly impact employee personality, the use of sound selection methods and a good match between employees and jobs will ensure people are selected and placed into jobs most appropriate for them, which, in turn, will help enhance their job satisfaction.

\section{Cultural Influences}

In terms of other influences on employee attitudes, there is also a small, but growing body of research on the influences of culture or country on employee attitudes and job satisfaction. The continued globalization of organizations poses new challenges for HR practitioners, and the available research on cross-cultural organizational and human resources issues can help them better understand and guide practice (Erez, 1994; House, 1995; Triandis, 1994).

The most cited cross-cultural work on employee attitudes is that of Hofstede (1980, 1985). He conducted research on employee attitude data in 67 countries and found that the data grouped into four major dimensions and that countries systematically varied along these dimensions. The four cross-cultural dimensions are: (1) individualism-collectivism; (2) uncertainty avoidance versus risk taking; (3) power distance, or the extent to which power is unequally distributed; and (4) masculinity/femininity, more recently called achievement orientation. For example, the United States was found to be high on individualism, low on power distance, and low on uncertainty avoidance (thus high on risk taking), whereas Mexico was high on collectivism, high on power distance, and high on uncertainty avoidance.

The four dimensions have been a useful framework for understanding cross-cultural differences in employee attitudes, as well as recognizing the importance of cultural causes of employee attitudes. More recent analyses have shown that country/culture is as strong a predictor of employee attitudes as the type of job a person has (Saari, 2000; Saari \& Erez, 2002; Saari \& Schneider, 2001).

There have been numerous replications of Hofstede's research (reviewed by Sondergaard, 1994). The importance of culture has also been found in how employees are viewed and valued across countries/cultures (Jackson, 2002)—countries systematically vary on the extent to which they view employees in instrumental versus humanistic ways. In terms of practical recommendations, an awareness of, and, whenever possible, adjustments to, cultural factors that influence employee attitudes and measurement are important for HR practitioners as employee attitude surveys increasingly cross national boundaries.

\section{Work Situation Influences}

As discussed earlier, the work situation also matters in terms of job satisfaction and organization impact. Contrary to some commonly held practitioner beliefs, the most notable situational influence on job satisfaction is the nature of the work itself-often called "intrinsic job characteristics." Research studies across many years, organizations, and types of jobs show that when employees are asked to evaluate different facets of their job such as supervision, pay, promotion opportunities, coworkers, and so forth, the nature of the work itself generally emerges as the most important job facet (Judge \& Church, 2000; Jurgensen, 1978). This is not to say that well-designed compensation programs or effective supervision are unimportant; rather, it is that much can be done to influence job satisfaction by ensuring work is as interesting and challenging as possible. Unfortunately, some managers think employees are most desirous of pay to the exclusion of other job attributes such as interesting work. For example, in a study examining the importance of job attributes, employees ranked interesting work as the most important job attribute and good wages ranked fifth, whereas when it came to what managers thought employees wanted, good wages ranked first while interesting work ranked fifth (Kovach, 1995).

Of all the major job satisfaction areas, satisfaction with the nature of the work itself-which includes job challenge, autonomy, variety, and scope-best predicts overall job satisfaction, as well as other important outcomes like employee retention (e.g., Fried

\author{
Even though \\ organizations \\ cannot directly \\ impact \\ employee \\ personality, the \\ use of sound \\ selection \\ methods and a \\ good match \\ between \\ employees and \\ jobs will ensure \\ people are \\ selected and \\ placed into jobs \\ most \\ appropriate for \\ them, which, in \\ turn, will help \\ enhance their \\ job satisfaction.
}


We hear

debates and

confusion about

whether

satisfied

employees are

productive

employees, and

HR

practitioners

rightfully

struggle as they

must reduce

costs and are

concerned

about the

effects on job

satisfaction

and, in turn,

the impact on

performance

and other

outcomes.
\& Ferris, 1987; Parisi \& Weiner, 1999; Weiner, 2000). Thus, to understand what causes people to be satisfied with their jobs, the nature of the work itself is one of the first places for practitioners to focus on.

\section{Gap 2-The Results of Positive or Negative Job Satisfaction}

A second major practitioner knowledge gap is in the area of understanding the consequences of job satisfaction. We hear debates and confusion about whether satisfied employees are productive employees, and HR practitioners rightfully struggle as they must reduce costs and are concerned about the effects on job satisfaction and, in turn, the impact on performance and other outcomes. The focus of our discussion in this section is on job satisfaction, because this is the employee attitude that is most often related to organizational outcomes. Other employee attitudes, such as organizational commitment, have been studied as well, although they have similar relationships to outcomes as job satisfaction.

\section{Job Satisfaction and Job Performance}

The study of the relationship between job satisfaction and job performance has a controversial history. The Hawthorne studies, conducted in the 1930s, are often credited with making researchers aware of the effects of employee attitudes on performance. Shortly after the Hawthorne studies, researchers began taking a critical look at the notion that a "happy worker is a productive worker." Most of the earlier reviews of the literature suggested a weak and somewhat inconsistent relationship between job satisfaction and performance. A review of the literature in 1985 suggested that the statistical correlation between job satisfaction and performance was about .17 (Iaffaldano \& Muchinsky, 1985). Thus, these authors concluded that the presumed relationship between job satisfaction and performance was a "management fad" and "illusory." This study had an important impact on researchers, and in some cases on organizations, with some managers and HR practitioners concluding that the relationship between job satisfaction and performance was trivial.

However, further research does not agree with this conclusion. Organ (1988) suggests that the failure to find a strong relationship between job satisfaction and performance is due to the narrow means often used to define job performance. Organ argued that when performance is defined to include important behaviors not generally reflected in performance appraisals, such as organizational citizenship behaviors, its relationship with job satisfaction improves. Research tends to support Organ's proposition in that job satisfaction correlates with organizational citizenship behaviors (Organ \& Ryan, 1995).

In addition, in a more recent and comprehensive review of 301 studies, Judge, Thoresen, Bono, and Patton (2001) found that when the correlations are appropriately corrected (for sampling and measurement errors), the average correlation between job satisfaction and job performance is a higher .30. In addition, the relationship between job satisfaction and performance was found to be even higher for complex (e.g., professional) jobs than for less complex jobs. Thus, contrary to earlier reviews, it does appear that job satisfaction is, in fact, predictive of performance, and the relationship is even stronger for professional jobs.

\section{Job Satisfaction and Life Satisfaction}

An emerging area of study is the interplay between job and life satisfaction. Researchers have speculated that there are three possible forms of the relationship between job satisfaction and life satisfaction: (1) spillover, where job experiences spill over into nonwork life and vice versa; (2) segmentation, where job and life experiences are separated and have little to do with one another; and (3) compensation, where an individual seeks to compensate for a dissatisfying job by seeking fulfillment and happiness in his or her nonwork life and vice versa. Judge and Watanabe (1994) argued that these different models may exist for different individuals and were able to classify individuals into the three groups. On the basis of a national sample of U.S. workers, they found 68\% were the spillover group, $20 \%$ 
in the segmentation group, and $12 \%$ in the compensation group. Thus, the spillover model, whereby job satisfaction spills into life satisfaction and vice versa, appears to characterize most U.S. employees.

Consistent with the spillover model, a review of the research literature indicated that job and life satisfaction are correlated (average true score correlation: .44; Tait, Padgett, \& Baldwin, 1989). Since a job is a significant part of one's life, the relationship between job satisfaction and life satisfaction makes sense-one's job experiences spill over into one's life. However, it also seems possible the causality could go the other way-a happy or unhappy life spills over into one's job experiences and evaluations. In fact, the research suggests that the relationship between job and life satisfaction is reciprocal-job satisfaction does affect life satisfaction, but life satisfaction also affects job satisfaction (Judge \& Watanabe, 1994).

Also in support of a spillover model for job and life satisfaction, the research literature shows a consistent relationship between job satisfaction and depression (Thomas \& Ganster, 1995). One might speculate on the possibility that the relationship is simply due to personality traits that cause both low job satisfaction and depression. However, to counter this, there is evidence that job loss and other work events are in fact associated with depression (Wheaton, 1990). Thus, this research suggests that dissatisfaction resulting from one's job can spill over into one's psychological well-being.

Based on this research, one conclusion is that organizations only have so much control over a person's job satisfaction, because for many people, their job satisfaction is a result, in part, of spillover of their life satisfaction. However, continuing to take actions to address low job satisfaction is not only important for organizational effectiveness, but by not doing so, organizations can cause spillover of employees' low job satisfaction into their life satisfaction and well-being.

\section{Job Satisfaction and Withdrawal Behaviors}

Numerous studies have shown that dissatisfied employees are more likely to quit their jobs or be absent than satisfied employees (e.g., Hackett \& Guion, 1985; Hulin, Roznowski, \& Hachiya, 1985; Kohler \& Mathieu, 1993). Job satisfaction shows correlations with turnover and absenteeism in the -.25 range. Job dissatisfaction also appears to be related to other withdrawal behaviors, including lateness, unionization, grievances, drug abuse, and decision to retire.

Hulin et al. (1985) have argued that these individual withdrawal behaviors are all manifestations of "job adaptation" and have proposed that these individual behaviors be grouped together. Because the occurrence of most single withdrawal behaviors is quite low, looking at a variety of these behaviors improves the ability for showing the relationship between job attitudes and withdrawal behaviors (Hulin, 1991). Rather than predicting isolated behaviors, withdrawal research and applied practice would do better, as this model suggests, to study patterns in withdrawal behaviors-such as turnover, absenteeism, lateness, decision to retire, etc.together. Several studies have supported this, showing that when various withdrawal behaviors are grouped together, job satisfaction better predicts these behavioral groupings than the individual behaviors.

Based on the research that shows job satisfaction predicts withdrawal behaviors like turnover and absenteeism, researchers have been able to statistically measure the financial impact of employee attitudes on organizations (e.g., Cascio, 1986; Mirvis \& Lawler, 1977). Using these methods can be a powerful way for practitioners to reveal the costs of low job satisfaction and the value of improved employee attitudes on such outcomes as absenteeism and retention.

\section{Gap 3-How To Measure and Influence Employee Attitudes}

The third major practitioner knowledge gap is in the area of how to measure and influence employee attitudes. There are a number of possible methods for measuring employee attitudes, such as conducting focus groups, interviewing employees, or carrying out employee surveys. Of these methods, the most accurate measure is a well-constructed em-
Numerous studies have shown that dissatisfied employees are more likely to quit their jobs or be absent than satisfied employees... 
...measures of job satisfaction can be faceted (such as the JDI)—whereby they measure various dimensions of the job-while others are global—or measure a single, overall feeling toward the job. ployee attitude survey. Thus, we first provide an overview of the major research on employee attitude surveys. To positively influence employee attitudes, understanding of some of the research already discussed is important. In addition, knowledge of important considerations for analyzing employee survey results is essential for taking appropriate steps to improve attitudes. Finally, practitioners often use survey feedback discussion meetings as a means for acting on employee attitude surveys - the final part of this section addresses research related to this topic and the most important ways to support action.

\section{Employee Attitude Surveys}

Two major research areas on employee attitude surveys are discussed below: employee attitude measures used in research and facet versus global measures. The areas discussed are not meant to provide knowledge of all relevant considerations for designing employee surveys, but rather provide background on the research and an overview of some major areas of study.

In the research literature, the two most extensively validated employee attitude survey measures are the Job Descriptive Index (JDI; Smith, Kendall, \& Hulin, 1969) and the Minnesota Satisfaction Questionnaire (MSQ; Weiss, Dawis, England, \& Lofquist, 1967). The JDI assesses satisfaction with five different job areas: pay, promotion, coworkers, supervision, and the work itself. The JDI is reliable and has an impressive array of validation evidence. The MSQ has the advantage of versatility-long and short forms are available, as well as faceted and overall measures. Another measure used in job satisfaction research (e.g., Judge, Erez, Bono, \& Thoresen, in press) is an updated and reliable five-item version of an earlier scale by Brayfield and Rothe (1951). All of these measures have led to greater scientific understanding of employee attitudes, and their greatest value may be for research purposes, yet these measures may be useful for practitioners as well. In practice, organizations often wish to obtain a more detailed assessment of employee attitudes and/or customize their surveys to assess issues unique to their firm.
There are two additional issues with measuring employee attitudes that have been researched and provide potentially useful knowledge for practitioners. First, measures of job satisfaction can be faceted (such as the JDI)—whereby they measure various dimensions of the job-while others are global-or measure a single, overall feeling toward the job. An example of a global measure is "Overall, how satisfied are you with your job?" If a measure is facet-based, overall job satisfaction is typically defined as a sum of the facets. Scarpello and Campbell (1983) found that individual questions about various aspects of the job did not correlate well with a global measure of overall job satisfaction. However, if one uses job satisfaction facet scores-based on groups of questions on the same facet or dimension rather than individual questions - to predict an independent measure of overall job satisfaction, the relationship is considerably higher. As has been noted elsewhere (e.g., Judge \& Hulin, 1993), job satisfaction facets are sufficiently related to suggest that they are measuring a common construct-overall job satisfaction.

Second, while most job satisfaction researchers have assumed that overall, singleitem measures are unreliable and therefore should not be used, this view has not gone unchallenged. Wanous, Reichers, and Hudy (1997) found that the reliability of singleitem measures of job satisfaction is .67. For the G. M. Faces scale, another single-item measure of job satisfaction that asks individuals to check one of five faces that best describes their overall satisfaction (Kunin, 1955), the reliability was estimated to be .66 . Therefore, respectable levels of reliability can be obtained with an overall measure of job satisfaction, although these levels are somewhat lower than most multiple-item measures of job satisfaction.

Based on the research reviewed, there is support for measuring job satisfaction with either a global satisfaction question or by summing scores on various aspects of the job. Therefore, in terms of practice, by measuring facets of job satisfaction, organizations can obtain a complete picture of their specific strengths and weaknesses related to 
employee job satisfaction and use those facet scores for an overall satisfaction measure, or they can reliably use overall satisfaction questions for that purpose.

Analyzing and Interpreting Survey Results for Action

Effective analysis and interpretation of employee attitude survey data is necessary in order to understand the results and, in turn, take appropriate actions to improve employee attitudes and job satisfaction. Research on employee attitude measurement and statistical analyses is a key contribution of the field of psychology (e.g., Edwards, 2001; Macey, 1996). Highlights of the research on survey analyses and the most important issues for HR practitioners to consider are reviewed below.

The Use of Norms. Ratings made by employees on survey questions can systematically vary - and vary widely - no matter what company they work for. For example, ratings of pay are typically low and ratings of workgroup cooperation are typically rated very high. Similar systematic variations are found when comparing survey data for many companies across countries. For example, Switzerland tends to have some of the highest ratings, Italy some of the lowest. Therefore, it is helpful when interpreting survey data to know how the survey results compare to industry norms or country norms. Survey norms are descriptive statistics that are compiled from data on the same survey questions from a number of companies and are obtained by joining a consortium. Comparability of the companies, company size, and number of companies are important factors in the value of the norms (Morris \& LoVerde, 1993). In addition, the professionalism in the norms process and the age of the norms will affect their relevance and accuracy (Bracken, 1992; R. H. Johnson, 1996). If survey norms are not an option, overall company or unit results can serve as internal norms, although they encourage an inward focus and potentially internal competition. Actions determined through normed-based comparisons can be strong drivers of change and help focus a company externally to other companies and the competition.

Comparisons and Numerical Accuracy. Comparing data is one of the most useful survey analysis techniques, such as described above for using norms to compare a company's survey results to other companies. Comparisons for the same organization or unit over time with a trended survey are also valuable to measure progress. At the same time, comparisons must be done with professional care, taking into account measurement issues (Cascio, 1986). This is one of the major areas of practitioner misinterpretation in our experience.

Of particular concern are organizations using unreliable survey data, based on low numbers of survey respondents and/or department size, to compare departments/managers or to inappropriately measure change over time. In general, the lower the number, the greater the effects of random error on data, like the differences between flipping a coin 10 times versus 1,000 times. Thus, comparisons of groups or departments with small numbers generally should not be done, especially when the survey is a sample survey and designed to provide data only at higher levels. Even for surveys of all employees that provide survey results to each manager/department, numerical accuracy is still of concern and comparisons across time or between managers should be avoided - data at the workgroup level is best provided to each manager for department feedback and local actions. To avoid these measurement issues, it is helpful to have a lower limit on the organization size and/or number of respondents needed to create reports for comparisons (most organizations we have worked with set this at a maximum margin of error of plus/minus 9 percentage points, which is generally around 100 respondents). Numerical accuracy and appropriate comparisons are especially important when using survey data for performance targets and employment-related decisions.

Global Considerations. For organizations operating in more than one country, understanding survey data by country is also valu-

\author{
...it is helpful \\ when \\ interpreting \\ survey data to \\ know how the \\ survey results \\ compare to \\ industry norms \\ or country \\ norms.
}


One of the newest areas of research that assists with identifying important areas for survey action is to statistically link employee attitudes to business outcomes. able for improving employee attitudes. However, making comparisons across countries is another type of analysis that should be conducted with caution. As stated earlier, there are country/cultural influences on employee attitudes, and the use of country norms is preferable. In other words, comparisons are best made against an appropriate country norm rather than comparing one country's survey results to another country's results. In addition to cultural factors, linguistic factors across countries can affect survey results (Ryan, Chan, Ployhart, \& Slade, 1999). Concepts-such as "employee recognition"-can have different meanings due to different cultural meanings (Hui, 1990; Hui \& Triandis, 1985), and this can affect the equivalence of the measurements of employee attitudes across countries. To help minimize linguistic and other issues, professional translations, back translations (translations back into English then checked against the original English), and country reviews are recommended. Other guidance on administrative and practical issues when conducting a multinational employee attitude survey is also available (e.g., S. R. Johnson, 1996).

Linking Employee Attitudes to Business Measures. One of the newest areas of research that assists with identifying important areas for survey action is to statistically link employee attitudes to business outcomes. This research is an extension of the research discussed earlier that correlated job satisfaction with job performance. Schneider and his colleagues carried out the groundbreaking studies in this area, showing how employee attitudes about various human resources practices correlated with customer satisfaction measures, thus indicating key levers to improve customer satisfaction. For example, they found that when employees reported higher satisfaction with work facilitation and career development, customers reported higher service quality (Schneider \& Bowen, 1985). Other researchers (e.g., Wiley, 1996) have developed linkage models that identify the organizational practices-as rated by employee attitude surveys - that relate to high levels of organizational performance. In addition, a variety of studies have shown how employee attitudes are predictive of important financial performance measures, such as market share (e.g., Ashworth, Higgs, Schneider, Shepherd, \& Carr, 1995; Colihan \& Saari, 2000; Harter, Schmidt, \& Hayes, 2002).

Linkage research can be done in any organization where there is some way to group enough survey data-such as in stores, branches, districts, and even countries-and then correlate it with financial and/or customer data for the same groups. This type of survey measurement and analysis helps practitioners demonstrate the impact of employee attitudes on the business, as well as identify key levers for action.

\section{Survey Feedback and Action}

Employee surveys, used effectively, can be catalysts for improving employee attittudes and producing organizational change. This statement is based on two important assumptions, both supported by research already reviewed in this article: first, that employee attitudes affect behavior and second, that employee attitudes are important levers of organizational performance.

Survey feedback and action help support and drive organizational change, and the "ability to manage change" is evaluated by line managers as the most important competency for HR professionals (Ulrich, Brockbank, Yeung, \& Lake, 1995). There are many variations of survey feedback and action, though an important research finding is that participation in feedback sessions alone will not result in change-and this is often where organizations fall short. In fact, Rynes et al. (2002) found that one of the highest percentages of HR professionals responding contrary to the research facts was to the statement "Ensuring employees participate in decision making is more important for improving organizational performance than setting performance goals." Extensive research does not support this statement, yet $82 \%$ of HR professionals marked it as true. In fact, actual action, not just involvement in survey feedback discussions and the development of plans, is critical for an employee survey to result in improved performance. Feedback sessions that result in concrete goals and result- 
ing actions have the most impact. This is supported by extensive research on goal-setting theory, which shows that having specific goals is a major factor for motivation and performance (Locke, Feren, McCaleb, Shaw, \& Denny, 1980; Locke \& Latham, 2002).

\section{How To Close the Gaps and Evaluate the Effectiveness of Practice}

Throughout this article, as we discussed the relevant research for each of the three knowledge gaps, we provided suggestions for closing the gaps. In this section, we offer some final suggestions, as well as ideas for evaluating the effectiveness of implemented practices.

One important way to close the gap between research and practice is to be better informed about the research. Given the demands on HR practitioners' time, this is a difficult task, yet one that is increasingly expected of HR professionals. Today, organizations need more from HR than someone to administer the tactical aspects of an employee survey and to check that managers are holding feedback discussions and have action plans. Organizations need HR practitioners who know how to develop effective and research-based employee attitude measures, understand and derive valuable insights from the data, and use the results to improve employee attitudes and job performance and help lead organizational change. There are many excellent and emerging ways to gain this knowledge-professional HR organizations (e.g., the Society for Human Resource Management) are increasingly offering ways to get summarized research information, and new ways to gain knowledge through online and other methods are emerging.

Another suggestion relates to improving knowledge of basic statistics. The need to measure, understand, and improve employee attitudes is essential for organizations of today. Yet, without the numeric comfort needed to fully understand and discuss employee attitude measurements, what they mean, and how they relate to other business measures, HR cannot be at the table to assist with achieving this goal.
In terms of evaluating the practices discussed in this article, the most rigorous and defensible methods are to apply return on investment (ROI) principles. These involve defining the objectives of a program-such as assess employee attitudes that predict organizational performance and improve employee attitudes and job satisfaction-and then evaluating, through appropriate research designs and measurements, whether these objectives were met. Approaches for carrying out ROI and cost-based evaluations are described in the literature (e.g., Cascio, 1986). These evaluation approaches are the most rigorous, yet can be resource- and time-intensive.

In terms of more straightforward suggestions for evaluating the practices implemented, we offer the following questions that HR practitioners can ask themselves: "Do we have an employee attitude survey that measures areas important for employee job satisfaction as well as organizational success?" "How do we know this and make this case to line management?" "Is the survey routinely used as part of decision making?" "Is the survey a respected source of information about the people side of the business?" "Am I at the table with line management using the survey insights for needed action and organizational change?" "Can I discuss these measures in light of other key business measures?" These may be new evaluation criteria for many HR professionals who have traditionally evaluated themselves in areas such as attitude survey response rates, timeliness of action plans submitted by managers, and the number of reports distributed. In the end, the evaluation of the practices implemented should consider these two important points: Are measures of employee attitude used as important information for the business? Ultimately, do employee attitudes and job satisfaction move in the desired direction?

\section{Conclusions and Future Directions}

The field of industrial/organizational psychology has a long, rich, and, at times, controversial history related to the study and understanding of employee attitudes and job
Today, organizations need more from HR than someone to administer the tactical aspects of an employee survey and to check that managers are holding feedback discussions and have action plans. 
satisfaction. Some of this research is very specific and aimed primarily at other researchers, while other publications provide practical guidance on understanding, measuring, and improving employee attitudes (e.g., Edwards \& Fisher, 2004; Kraut, 1996).

One likely future direction of employee attitude research will be to better understand the interplay between the person and the situation and the various internal and external factors that influence employee attitudes. In particular, a better understanding of the role of emotion, as well as broader environmental impacts, is needed and has been largely overlooked in past research.

In addition, ongoing research will provide more in-depth understanding of the effects of employee attitudes and job satisfaction on organizational measures, such as customer satisfaction and financial measures. Greater insights on the relationship between employee attitudes and business performance will assist HR professionals as they strive to enhance the essential people side of the business in a highly competitive, global arena.

LISE M. SAARI, PhD, is the director of global workforce research for IBM. Previously, she was the senior manager of people research at Boeing and, prior to that, a research scientist at the Battelle Research Institute. Dr. Saari has authored numerous articles, chapters, and presentations on employee attitudes and motivation. She served on the board of the Mayflower Group, a consortium of companies engaged in professional surveys. She also has served on the editorial boards for the Journal of Applied Psychology and Personnel Psychology. Dr. Saari is a member of the International Association of Applied Psychology, the European Congress of Work and Organizational Psychologists, and the Society for I-O Psychology.

Tiмothy A. Judge, PhD, is the Matherly-McKethan Eminent Scholar, Department of Management, Warrington College of Business, University of Florida. He holds a bachelor of business administration degree from the University of Iowa, and master's and doctoral degrees from the University of Illinois. Dr. Judge worked as a manager at Kohl's Department Stores and was formerly a full professor at the University of Iowa and associate professor at Cornell University. His research interests are in personality, leadership and influence behaviors, staffing, and job attitudes. He serves on the editorial review boards of the Journal of Applied Psychology, Personnel Psychology, and Organizational Behavior and Human Decision Processes.

\section{REFERENCES}

Arvey, R. D., Bouchard, T. J., Segal, N. L., \& Abraham, L. M. (1989). Job satisfaction: Environmental and genetic components. Journal of Applied Psychology, 74, 187-192.

Ashworth, S. D., Higgs, C., Schneider, B., Shepherd, W., \& Carr, L. S. (1995, May). The linkage between customer satisfaction data and employee-based measures of a company's strategic business intent. Paper presented at the Tenth Annual Conference of the Society for Industrial and Organizational Psychology, Orlando, FL.
Bracken, D. W. (1992). Benchmarking employee attitudes. Training and Development Journal, 46, 49-53.

Brayfield, A. H., \& Rothe, H. F. (1951). An index of job satisfaction. Journal of Applied Psychology, 35, 307-311.

Brief, A. P. (1998). Attitudes in and around organizations. Thousand Oaks, CA: Sage.

Cascio, W. F. (1986). Managing human resources: Productivity, quality of work life, profits. New York: McGraw-Hill.

Colihan, J., \& Saari, L. M. (2000). Linkage research: A global, longitudinal approach over 12 "web years.” In J. W. Wiley (Chair), Linking 
employee, customer, and business measures: Longitudinal insights and implications. Symposium conducted at the Fifteenth Annual Conference of the Society for Industrial and Organizational Psychology, New Orleans, LA.

Davis-Blake, A., \& Pfeffer, J. (1989). Just a mirage: The search for dispositional effects in organizational research. Academy of Management Review, 14, 385-400.

Edwards, J. E. (2001). Digging deeper to better understand and interpret employee survey result. Paper presented at the Sixteenth Annual Conference of the Society for Industrial and Organizational Psychology, San Diego, CA.

Edwards, J. E., \& Fisher, B. M. (2004). Evaluating employee survey programs. In J. E. Edwards, J. C. Scott, \& N. S. Raju (Eds.), The human resources program-evaluation handbook (pp. 365-386). Thousand Oaks, CA: Sage.

Erez, M. (1994). Toward a model of cross-cultural industrial and organizational psychology. In H. C. Triandis, M. D. Dunnette, \& L. M. Hough (Eds.), Handbook of industrial and organizational psychology (Vol. 4, pp. 559-608). Palo Alto, CA: Consulting Psychologists Press.

Fried, Y., \& Ferris, G. R. (1987). The validity of the job characteristics model: A review and metaanalysis. Personnel Psychology, 40(2), 287-322.

Hackett, R. D., \& Guion, R. M. (1985). A re-evaluation of the absenteeism-job satisfaction relationship. Organizational Behavior and Human Decision Processes, 35, 340-381.

Harter, J. K., \& Creglow, A. (1998). A meta-analysis and utility analysis of the relationship between core employee perceptions and business outcomes. Princeton, NJ: SRI/Gallup.

Harter, J. W., Schmidt, F. L., \& Hayes, T. L. (2002). Business-unit-level relationship between employee satisfaction, employee engagement, and business outcomes: A meta-analysis. Journal of Applied Psychology, 87, 268-279.

Hofstede, G. (1980). Culture's consequences: International differences in work-related values. Newbury Park, CA: Sage.

Hofstede, G. (1985). The interaction between national and organizational value systems. Journal of Management Studies, 22, 347-357.

House, R. J. (1995). Leadership in the twenty-first century: A speculative inquiry. In A. Howard (Ed.), The changing nature of work. San Francisco: Jossey-Bass.

House, R. J., Shane, S. A., \& Herold, D. M. (1996).
Rumors of the death of dispositional research are vastly exaggerated. Academy of Management Review, 21, 203-224.

Hui, C. H. (1990). Work attitudes, leadership styles and managerial behaviour indifferent cultures. In R. W. Brislin (Ed.), Applied cross-cultural psychology (pp. 186-208). Newbury Park, CA: Sage.

Hui, C. H., \& Triandis, H. C. (1985). Measurement in cross-cultural psychology: A review and comparison of strategies. Journal of Cross-Cultural Psychology, 16, 131-152.

Hulin, C. L. (1991). Adaptation, persistence, and commitment in organizations. In M. D. Dunnette \& L. M. Hough (Eds.), Handbook of industrial and organizational psychology (Vol. 2, pp. 445-505). Palo Alto, CA: Consulting Psychologists Press.

Hulin, C. L., Roznowski, M., \& Hachiya, D. (1985). Alternative opportunities and withdrawal decisions: Empirical and theoretical discrepancies and an integration. Psychological Bulletin, 97, 233-250.

Iaffaldano, M. R., \& Muchinsky, P. M. (1985). Job satisfaction and job performance: A meta-analysis. Psychological Bulletin, 97, 251-273.

Jackson, T. (2002). The management of people across cultures: Valuing people differently. Human Resource Management, 41, 455-475.

Johnson, R. H. (1996). Life in the consortium: The Mayflower Group. In A. I. Kraut (Ed.), Organizational surveys: Tools for assessment and change (pp. 285-309). San Francisco: Jossey-Bass.

Johnson, S. R. (1996). The multinational opinion survey. In A. I. Kraut (Ed.), Organizational surveys: Tools for assessment and change (pp. 310-329). San Francisco: Jossey-Bass.

Judge, T. A., \& Bono, J. E. (2001). Relationship of core self-evaluations traits-self-esteem, generalized self-efficacy, locus of control, and emotional stability — with job satisfaction and job performance: A meta-analysis. Journal of Applied Psychology, 86, 80-92.

Judge, T. A., \& Church, A. H. (2000). Job satisfaction: Research and practice. In C. L. Cooper \& E. A. Locke (Eds.), Industrial and organizational psychology: Linking theory with practice (pp. 166-198). Oxford, UK: Blackwell.

Judge, T. A., Erez, A., Bono, J. E., \& Thoresen, C. J. (in press). The core self-evaluation scale (CSES): Development of a measure. Personnel Psychology. 
Judge, T. A., Heller, D., \& Mount, M. K. (2002). Five-factor model of personality and job satisfaction: A meta-analysis. Journal of Applied Psychology, 87, 530-541.

Judge, T. A., \& Hulin, C. L. (1993). Job satisfaction as a reflection of disposition: A multiple-source causal analysis. Organizational Behavior and Human Decision Processes, 56, 388-421.

Judge, T. A., Locke, E. A., Durham, C. C., \& Kluger, A. N. (1998). Dispositional effects on job and life satisfaction: The role of core evaluations. Journal of Applied Psychology, 83, 17-34.

Judge, T. A., Thoresen, C. J., Bono, J. E., \& Patton, G. K. (2001). The job satisfaction-job performance relationship: A qualitative and quantitative review. Psychological Bulletin, 127, 376-407.

Judge, T. A., \& Watanabe, S. (1994). Individual differences in the nature of the relationship between job and life satisfaction. Journal of Occupational and Organizational Psychology, 67, 101-107.

Jurgensen, C. E. (1978). Job preferences (What makes a job good or bad?). Journal of Applied Psychology, 63, 267-276.

Kohler, S. S., \& Mathieu, J. E. (1993). An examination of the relationship between affective reactions, work perceptions, individual resource characteristics, and multiple absence criteria. Journal of Organizational Behavior, 14, 515-530.

Kovach, K. A. (1995). Employee motivation: Addressing a crucial factor in your organization's performance. Employment Relations Today, 22, 93-107.

Kraut, A. I. (1996). Organizational surveys: Tools for assessment and change. San Francisco: JosseyBass.

Kunin, T. (1955). The construction of a new type of attitude measure. Personnel Psychology, 8, 65-77.

Locke, E. A. (1976). The nature and causes of job satisfaction. In M. D. Dunnette (Ed.), Handbook of industrial and organizational psychology (pp. 1297-1349). Chicago: Rand McNally.

Locke, E. A., Feren, D. B., McCaleb, V. M., Shaw, K. N., \& Denny, A. T. (1980). The relative effectiveness of four methods of motivating employee performance. In K. D. Duncan, M. M. Gruneberg, \& D. Wallis (Eds.), Changes in working life (pp. 363-388). London: Wiley.
Locke, E. A., \& Latham, G. P. (2002). Building a practically useful theory of goal setting and task motivation: A 35-year odyssey. American Psychologist, 57, 705-717.

Macey, W. H. (1996). Dealing with the data: Collection, processing, and analysis. In A. I. Kraut (Ed.), Organizational surveys: Tools for assessment and change (pp. 204-232). San Francisco: Jossey-Bass.

Mirvis, P. H., \& Lawler, E. E. (1977). Measuring the financial impact of employee attitudes. Journal of Applied Psychology, 62, 1-8.

Morris, G. W., \& LoVerde, M. A. (1993). Consortium surveys. American Behavioral Scientist, 36, 531-550.

Motowidlo, S. J. (1996). Orientation toward the job and organization: A theory of individual differences in job satisfaction. In K. R. Murphy (Ed.), Individual differences and behavior in organizations (pp. 175-208). San Francisco: Jossey-Bass.

Organ, D. W. (1988). A restatement of the satisfaction-performance hypothesis. Journal of Management, 14, 547-557.

Organ, D. W., \& Ryan, K. (1995). A meta-analytic review of attitudinal and dispositional predictors of organizational citizenship behavior. Personnel Psychology, 48, 775-802.

Parisi, A. G., \& Weiner, S. P. (1999, May). Retention of employees: Country-specific analyses in a multinational organization. Poster at the Fourteenth Annual Conference of the Society for Industrial and Organizational Psychology, Atlanta, GA.

Ryan, A. M., Chan, D., Ployhart, R. E., \& Slade, A. L. (1999). Employee attitude surveys in a multinational organization: Considering language and culture in assessing measurement equivalence. Personnel Psychology, 52, 37-58.

Rynes, S. L., Colbert, A. E., \& Brown, K. G. (2002). HR professionals' beliefs about effective Human resource practices: Correspondence between research and practice. Human Resource Management, 41, 149-174.

Saari, L. M. (1999). Global perspectives in service quality. Paper presented at the Fourteenth Annual Conference for Industrial and Organizational Psychology, Atlanta, GA.

Saari, L. M. (2000). Employee surveys and attitudes across cultures. In Business as unusual? Are I/O psychology practices applicable across culture? Paper presented at the Fifteenth Annual Con- 
ference of the Society for Industrial and Organizational Psychology, New Orleans, LA.

Saari, L. M., \& Erez, M. (2002). Cross-cultural diversity and employee attitudes. Paper presented at the Seventeenth Annual Conference of the Society for Industrial and Organizational Psychology, Toronto.

Saari, L. M., \& Schneider, B. (2001). Going global: Surveys and beyond. Professional workshop presented at the Sixteenth Annual Conference of the Society for Industrial and Organizational Psychology, San Diego, CA.

Scarpello, V., \& Campbell, J. P. (1983). Job satisfaction: Are all the parts there? Personnel Psychology, 36, 577-600.

Schneider, B., \& Bowen, D. E. (1985). Employee and customer perceptions of service in banks: Replication and extension. Journal of Applied Psychology, 70, 423-433.

Smith, P. C., Kendall, L. M., \& Hulin, C. L. (1969). The measurement of satisfaction in work and retirement. Chicago: Rand McNally.

Sondergaard, M. (1994). Research note: Hofstede's consequences: A study of reviews, citations and replications. Organization Studies, 15, 447-456.

Staw, B. M., Bell, N. E., \& Clausen, J. A. (1986). The dispositional approach to job attitudes: A lifetime longitudinal test. Administrative Science Quarterly, 31, 437-453.

Staw, B. M., \& Ross, J. (1985). Stability in the midst of change: A dispositional approach to job attitudes. Journal of Applied Psychology, 70, 469-480.

Tait, M., Padgett, M. Y., \& Baldwin, T. T. (1989). Job and life satisfaction: A reevaluation of the strength of the relationship and gender effects as a function of the date of the study. Journal of Applied Psychology, 74, 502-507.

Thomas, L. T., \& Ganster, D. C. (1995). Impact of family-supportive work variables on work-family conflict and strain: A control perspective. Journal of Applied Psychology, 80, 6-15.

Triandis, H. C. (1994). Cross-cultural industrial and organizational psychology. In H. C. Triandis, M. D. Dunnette, \& L. M. Hough (Eds.), Handbook of industrial and organizational psychology (Vol. 4, pp. 103-172). Palo Alto, CA: Consulting Psychologists Press.

Ulrich, D., Brockbank, W., Yeung, A. K., \& Lake, D. G. (1995). Human resource competencies: An empirical assessment. Human Resource Management, 34, 473-495.

Wanous, J. P., Reichers, A. E., \& Hudy, M. J. (1997). Overall job satisfaction: How good are singleitem measures? Journal of Applied Psychology, 82, 247-252.

Weiner, S. P. (2000, April). Worldwide technical recruiting in IBM: Research and action. In P. D. Bachiochi (Chair), Attracting and keeping top talent in the high-tech industry. Practitioner Forum at the Fifteenth Annual Conference of the Society for Industrial and Organizational Psychology, New Orleans, LA.

Weiss, D. J., Dawis, R. V., England, G. W., \& Lofquist, L. H. (1967). Manual for the Minnesota Satisfaction Questionnaire. Minneapolis: Industrial Relations Center, University of Minnesota.

Weiss, H. M., \& Cropanzano, R. (1996). Affective events theory: A theoretical discussion of the structure, causes, and consequences of affective experiences at work. Research in Organizational Behavior, 18, 1-74.

Wheaton, B. (1990). Life transitions, role histories, and mental health. American Sociological Review, 55, 209-223.

Wiley, J. W. (1996). Linking survey results to customer satisfaction and business performance. In A. I. Kraut (Ed.), Organizational surveys: Tools for assessment and change. San Francisco: Jossey-Bass. 